\title{
Steen Christiansen
}

\author{
Ted Nannicelli and Paul Yaberham: \\ Cognitive Media Theory. \\ New York: Routledge. 2014
}

\section{Greg Singh: \\ Feeling Film: Affect and Authenticity in Popular Cinema. \\ New York: Routledge. 2014}

MedieKultur 2016, 59, 172-175

\section{Published by SMID | Society of Media researchers In Denmark | www.smid.dk} The online version of this text can be found open access at www.mediekultur.dk

Cognitive Media Theory is an anthology that has been edited by Ted Nannicelli and Paul Taberham with the express purpose of showing the breadth and depth of cognitive approaches to what one might call moving image studies. The anthology primarily contains studies of film but also includes some television and video game articles. In the introduction, Nannicelli and Taberham tie the different articles together and try to accurately describe and define cognitive media theory. As a synthesis and overview it is not bad, but the four characteristic features that Nannicelli and Taberham ascribe to cognitive media theory are problematic:

1. a dedication to the highest standards of reasoning and evidence in film and media studies.

2. a commitment to stringent inter-theoretical criticism and debate.

3. a general focus on the mental activity of viewers as the central object of inquiry.

4. an acceptance of a naturalistic perspective, broadly construed. (4)

I cannot think of a single academic field that would not describe itself as adhering to the highest standards of reasoning. The two characteristics are thus redundant but also a peculiar argument. If cognitive media theory is dedicated to the highest standards of reasoning and stringently committed to inter-theoretical criticism, are we to take that to mean that 
Book review: Cognitive Media Theory \&

\section{Feeling Film: Affect and Authenticity in Popular Cinema}

other approaches to film studies do not adhere to a similarly stringent standard of reasoning? That is certainly an overbearing way of opening an argument.

The two other characteristics, however, seem right on the money. In this instance, mental activity means cognitive mental activity, and while it is based primarily on a cognitive psychological background, this approach often borrows from analytical philosophy. As with any large anthology, it is difficult to do justice to the width of arguments found here, but Dirk Eitzen's "Effects of Entertaining Violence" is a particularly subtle and nuanced example of how mental activity works - and does not work. Tackling the problematic issue of the effects of violence in media, Eitzen dives into the general aggression model to show that there is no direct correlation between violence, anti-social behavior and video games. Eitzen makes a significant and subtle distinction between priming and learning. While certain types of behavior are primed in playing Grand Theft Auto, what is learned can be quite different. Aggressive ideas and impulses are certainly primed, but our cognitive faculties also work to prime empathy, disgust, and concern for others (170-171). Whether or not we learn violent behavior or anti-violent behavior from violent video games is a matter of our wider environment (parents, peers, etc) and has relatively little to do with the video game in question.

Eitzen's work is an excellent example of the nuances cognitive media theory can tease out of media works, and it explains convincingly why one person can watch violent films and remain a functional person (me), while others turn psychopathic (James Eagan Holmes, for example). Mental activity is not limited to one activity but comprises a complex interweaving of many different impulses and impressions, and priming does not equate with expression. By truly paying attention to mental activity, cognitive media theory can convincingly explain part of how people act and behave.

The fourth characteristic, the acceptance of a naturalistic approach, is evident in the conceptual vocabulary employed by cognitive media theorists. Rather than employ existing terms, cognitive media theorists are more likely to draw terms and concepts from neuroscience and neuropsychology and rework them to fit film studies. In his article "The Pit of Naturalism", for instance, Murray Smith shows how the startle effect and empathy are cued by formal means in film. Discussing the impact of the startle effect in the opening scene of Iron Man, where the unexpected explosion serves as a contrast to the friendliness of Tony Stark, Smith clearly elucidates how one can apply this concept to film. Similarly with the concept of empathic mirroring, Smith draws on the presence of mirror neurons that tie humans together in sensate experience to understand our engagement with 127 Hours. While Smith's arguments about the film are convincing, what exactly is the purpose of employing the theory of mirror neurons? Smith seems to believe that it both makes the case for the presence of mirror neurons and reinforces his arguments about the film. Yet our response to the film can in no way prove or disprove the presence of mirror neurons, not do we need mirror neurons to discuss our empathic engagement with the film. Since Aristotle, the concept of mimesis has functioned as a way of understanding emotional 
Book review: Cognitive Media Theory \&

\section{Feeling Film: Affect and Authenticity in Popular Cinema}

responses. Drawing on a different conception of mimesis than the platonic concept of representation, cultural theorists have developed a mimetic understanding of art since Walter Benjamin. That neuroscience is only now catching up with cultural theory does not mean that mirror neurons are more convincing arguments; they are simply scientific explanations of what we already knew.

The emphasis on a naturalistic approach thus reveals a fundamental schism in cognitive media theory. Many cognitive media theorists are excellent media theorists but are poor neuroscientists. That mirror neurons are the scientific explanation for our emotional reactions to films (a fact I do not dispute) says absolutely nothing about the film in question. To use the presence of mirror neurons as an argument for how we feel abput 127 Hours is a foil: we have argued nothing, because mirror neurons are always present. Smith's argument about our sensate experience of 127 Hours convinces me, but not because of mirror neurons. To say that mirror neurons make us feel a particular way is a faux argument, since mirror neurons only explain that we feel, not what we feel. What we feel is contingent on the film's aesthetics. Until cognitive media theory can overcome this dependence on correlation with scientific findings, it will remain trapped in simply corroborating scientific findings in films. Eitzen's work is one example of how to move beyond mere corroboration, but Smith's is not.

Another path in film and media theory is what we might term the sensory one, of which Greg Singh's Feeling Film is an example. Singh's approach is different from the more dominant version of affect theory, which typically tends to be based on continental/speculative philosophy, extending from Spinoza via Deleuze to contemporary theorists such as Brian Massumi, Steven Shaviro and Barbara Kennedy. Instead, Singh draws on depth psychology, and especially on the work of Carl Jung. While this might appear to be a distinction without a difference, it turns out to be an important point for Singh. In contradistinction to Spinozist-Deleuzian approaches, Singh argues that affect is not pre-subjective: it is located squarely within the subject. Affects are ours and define us, rather than traversing and producing us.

What Singh is interested in, then, is the authenticity of feeling that is expressed in films and to which audiences subsequently respond. For Singh, authenticity is also quite distinct from cultural theory's typical use of the word as a construction; instead, authenticity suggests real, authentic feeling that resonates with audiences. For instance, in what he terms the Frat Pack cycle of films, and especially in I Love You, Man, mancaves and homosocial behaviors work to produce spaces for negotiating masculine identities because these cinematic spaces render feelings authentic. In sharp contrast to other discussions of affect in film, Singh primarily focuses on characters and story. Formal properties are rarely discussed and it is not clear what such discussions would even reveal, considering Singh's approach. Instead, Singh's approach is most appealing to those who are already interested in characters and story development. Social bonds and cultural interaction are at the forefront of Singh's analyses. 
Book review: Cognitive Media Theory \&

Feeling Film: Affect and Authenticity in Popular Cinema

For this reason, Singh's book stands in stark contrast to Cognitive Media Theory, even though both books appear to speak to our experience of films. Yet Singh, Nannicelli and Yaberham would have little to say to each other, considering the distance between Singh's interpretative stance that we can locate real human behavior in cinematic stories, on the one hand, and, on the other hand, the emphasis of the cognitive approach on objective analysis, with neuroscience as its primary method. What these very disparate approaches do show, however, is that film theory as a field is very much alive and well.

Steen Christiansen

Associate professor

Department of Culture and Global Studies

Aalborg University, Denmark

steen@cgs.aau.dk 